\section{Diagnosis of retinopathy in children younger than 12 years of age: implications for the diabetic eye screening guidelines in the UK}

A Hamid ${ }^{1}$, HM Wharton ${ }^{1}$, A Mills ${ }^{1}$, JM Gibson ${ }^{1,2}$, M Clarke ${ }^{1}$ and PM Dodson ${ }^{1,2}$

\begin{abstract}
Aim To assess whether the current starting age of $\mathbf{1 2}$ is suitable for diabetic retinopathy (DR) screening and whether diabetes duration should be taken into account when deciding at what age to start screening patients. Materials and methods A retrospective analysis of 143 patients aged 12 years or younger who attended diabetic eye screening for the first time in the Birmingham, Solihull and Black Country Diabetic Eye Screening Programme was performed.

Results The mean age of the patients was 10.7 (7-12) years with 73 out of 143 aged below 12 years and 70 were 12 years of age. $98 \%$ had type 1 diabetes and mean diabetes duration was 5 (1 month-11 years) years. For those younger than 12 years, $7 / 73(9.6 \%)$ had background DR (BDR), of these mean diabetes duration was 7 years (6-8). The youngest patient to present with DR was aged 8 years. In those aged 12 years, 5/70 (7.1\%) had BDR; of these mean diabetes duration was 8 years (6-11). No patient developed DR before 6 years duration in either group.

Conclusions The results show that no patient younger than the age of 12 had sight-threatening DR (STDR), but BDR was identified. Based on the current mission statement of the Diabetic Eye Screening Programme to identify STDR, 12 years of age is confirmed as the right age to start screening, but if it is important to diabetic management to identify first development of DR, then screening should begin after 6 years of diabetes diagnosis.

Eye (2016) 30, 949-951; doi:10.1038/eye.2016.59; published online 15 April 2016
\end{abstract}

\section{Introduction}

Diabetic retinopathy (DR) is one of the major complications of diabetes and is mainly associated with long duration diabetes. ${ }^{1-3}$ DR is a major cause of visual loss in the UK, and if left untreated, can lead to blindness.

Current literature suggests that children with diabetes do not typically develop sight-threatening DR (STDR) until puberty or older. ${ }^{4-7}$ However, DR can occur before puberty and adolescence, which are high risk periods for DR progression. ${ }^{1,4,8}$

The NHS Diabetic Eye Screening Programme in the UK states that all people with diabetes aged 12 years and older should be offered screening for STDR. This age was defined at the start of the programme in 2005 by a report which found that the youngest person to have STDR was 11.9 years old. ${ }^{9}$ Previous studies have been carried out to assess DR prevalence in young patients. The majority of these studies showed that a small percentage of patients younger than 12 years developed DR. $7,10,11$

The main aim of the audit was to assess whether the current starting age is appropriate in relation to identification of STDR. A secondary aim was to determine whether diabetes duration should be taken into account when deciding at what age to start screening for DR in children.

\section{Materials and methods}

This was a retrospective analysis of DR in patients aged 12 years or younger registered with the Birmingham, Solihull and Black Country Diabetic Eye Screening Programme (BSBCDESP). Screening was performed by
${ }^{1}$ Departments of Diabetes and Ophthalmology, Heartlands Hospital, Birmingham, UK

${ }^{2}$ School of Health and Life Sciences, Aston University, Birmingham, UK

Correspondence: A Hamid, Diabetes \& Endocrinology Centre, Birmingham Heartlands Hospital, Bordesley Green East, Birmingham B9 5SS, UK

Tel: +0121 424 3049;

Fax: +01214242982

E-mail: aisha.hamid@

heartofengland.nhs.uk

Received: 9 December 2015 Accepted in revised form: 10 February 2016 Published online: 15 April 2016

Previously presented at the Royal College of Ophthalmologists and EASDec conferences. 
accredited optometrists and screeners in optometry practices and hospital locations. During screening, best corrected visual acuity (VA) was measured using Snellen notation. A digital fundus camera was used to take two $45^{\circ}$ images (one macula-centred and one optic disc-centred) through dilated pupils in each eye. Grading was performed according to English national grading definitions ${ }^{12}$ and quality assured to National Diabetic Eye Screening Programme (NDESP) guidelines.

All patients who attended diabetic eye screening were aged 12 years or younger from 1 January 2003 to 31 December 2011 were included. If patients had attended multiple diabetic eye screening episodes during this period, their first screening result was used for analysis. According to NDESP, patients should be screened from the age of 12 years, but within the BSBCDESP patients, younger than 12 years had been referred for screening from local hospital paediatric diabetes departments. Paediatric diabetologists referred patients for their initial screen based on the age of diagnosis and diabetes duration.

The screening database was used to determine the patients' date of birth and age of first diabetic eye screen as well as VA and the screening result. The presence of any DR was considered as a screen-positive result in this analysis. Electronic hospital records were also used to determine the type of diabetes, date of diabetes diagnosis, and whether they were attending an outpatient paediatric diabetes clinic as part of their diabetes care.

Statistical analysis of diabetes duration was performed using the independent $t$-test, a $P$-value of $<0.05$ was considered significant.

\section{Results}

In total, 143 patients aged 12 years or younger were identified in the screening database. These included 78 (55\%) males and 65 (45\%) females. 140 (98\%) patients were found to have type 1 diabetes mellitus and 3 had type 2 diabetes mellitus (Table 1). The mean age at first diabetic eye screen was 10.7 years with the oldest patient being 12 years and 11 months and the youngest being 7 years and 4 months. Mean duration of diabetes at first screen was 5 years (range: 1 month-11 years). Most of the children (97\%) attended paediatric diabetic clinics regularly. Overall, the whole cohort had good VA with a mean VA of $6 / 5$ (range: 6/4-6/36) in the best eye. There were eight patients with VAs of $6 / 12$ or worse in at least one eye. The causes of these VAs were recorded by the screeners as amblyopia $(n=2)$, optic atrophy $(n=1)$, longstanding poor VA $(n=2)$, refractive causes $(n=2)$, and not recorded $(n=1)$.

A total of 12 patients (8.4\%) were screen-positive for DR. All 12 patients were found to have mild non-proliferative DR (R1) (and no maculopathy) in at least 1 eye. No patients
Table 1 Patient demographics of those patients aged 12 years and younger than 12 years

\begin{tabular}{ll}
\hline & $\mathrm{n}=143$ \\
\hline $\begin{array}{l}\text { Type of diabetes } \\
1\end{array}$ & \\
2 & $140(98 \%)$ \\
Mean age (range) & $3(2 \%)$ \\
Gender & 10.7 years $(7-12$ years) \\
Male & \\
Female & $78(55 \%)$ \\
Mean diabetes duration (range) & $65(45 \%)$ \\
$\begin{array}{l}\text { Mean visual acuity (range) } \\
\text { Patients attending diabetic } \\
\text { paediatric clinic }\end{array}$ & 5 years $(1$ month-11 years) \\
\hline
\end{tabular}

Table 2 Mean diabetes duration for those with or without DR

\begin{tabular}{|c|c|c|c|}
\hline & $\begin{array}{c}\text { Mean diabetes } \\
\text { duration } \\
\text { for those with } \\
\text { no DR (years) }\end{array}$ & $\begin{array}{c}\text { Mean diabetes } \\
\text { duration } \\
\text { for those with } \\
\text { DR (years) }\end{array}$ & P-value \\
\hline Aged 12 years, $(n=70)$ & 4.3 (1 month-11 years) & 8.2 (6-11 years) & 0.002 \\
\hline $\begin{array}{l}\text { Younger than } 12 \text { years, } \\
(n=73)\end{array}$ & 5.1 (6 months -9 years) & 6.6 (6-8 years) & 0.004 \\
\hline Total $(n=143)$ & 4.8 (1 month-11 years) & 7.3 (6-11 years) & 0.001 \\
\hline
\end{tabular}

Abbreviation: DR, diabetic retinopathy.

were identified with STDR. One patient was investigated for reduced vision of $6 / 12$ in the right eye and 6/18 in the left eye, and diagnosed with optic atrophy and no DR.

\section{Age}

To determine whether screening should take place before the age of 12, patients were divided into two groups: those younger than 12 years and those aged 12 years. There were 73 children in the younger-than-12 year group and 70 children in the aged 12 year group. There were more patients in the younger-than-12 year group who were screen-positive than those aged 12 years (7 (9.6\%): $5(7.1 \%))$, but this was not statistically significant. The youngest age of presentation with DR was 8 years old.

\section{Duration of diabetes}

A significant difference was seen in diabetes duration between those who presented with DR and those who did not (Table 2). The mean diabetes duration in those with DR was 7.3 years (range: $6-11$ years) compared with 4.8 years (range: 1 month-11 years) in those with no DR. DR was not seen in any patient who had diabetes duration of $<6$ years.

\section{Discussion}

This audit demonstrates that patients younger than 12 years do develop DR. The results were similar amongst those aged 12 years and those aged younger than 12 years, as both had a similar prevalence of BDR and none had STDR. This is in agreement with previous studies. ${ }^{1,2,10}$ 
Of importance, no patient was identified with DR with a diabetes duration of $<6$ years and indicates that longer duration of diabetes is a major predictor of DR development. This is well-established and the results from our audit are in accordance with this observation. 5,7,8,10,11,13

The decision on what age to start DR screening will be determined by the mission statement of a DR screening programme. ${ }^{7,14}$ If it is to detect STDR, then our data support 12 years of age to be the right age as demonstrated in our population. However, if it is important to identify first detection of development of DR, for example, to review diabetes medical management, then ideally DR screening should start 6 years after the onset of childhood diabetes. The mission statement of the NDESP is the former, thereby supporting the current English protocol of starting at 12 years of age.

The main limitation of this audit is that it is limited to a UK population. Ethnicity had not been accurately recorded, so could not be used in the analysis, and therefore may be different in other populations depending on ethnicity level of diabetic control. Those younger than 12 years may have selection bias as they were referred by paediatric diabetologists on the basis of age and duration, whereas the 12 -year-olds were automatically referred for screening from diabetes registers.

In conclusion, our data support the current guideline of screening from the age of 12 years to detect STDR. However, if the first detection of DR in a child is important, then screening should start 6 years after diabetes diagnosis.

\section{Summary}

\section{What was known before}

- There have been few previous studies that have assessed diabetic retinopathy (DR) prevalence in young patients, with the majority of the studies showing that a small percentage of patients younger than the age of $12 \mathrm{had}$ developed DR, but none have looked specifically at diabetes duration and whether this should be taken into account, when assessing if the current starting age of 12 is appropriate for diabetic screening.

\section{What this study adds}

- Screening in a population group of 12 years old or younger identifies that a significant proportion of patients had background DR (BDR), but no sight-threatening DR (STDR). Based on the current mission statement of the Diabetic Eye Screening Programme to identify STDR, 12 years of age is confirmed as the right age to start screening, but if it is important to diabetic management to identify first development of DR, then screening should begin after 6 years of diabetes diagnosis.

\section{Conflict of interest}

The authors declare no conflict of interest.

\section{References}

1 Joner G, Brinchmann-Hansen O, Torres CG, Hanssen KF. A nationwide cross-sectional study of retinopathy and microalbuminuria in young Norweigan type 1 (insulindependent) diabetic patients. Diabetologia 1992; 35: 1049-1054.

2 Lueder GT, Pradhan S, White NH. Risk of retinopathy in children with type 1 diabetes mellitus before 2 years of age. Am J Ophthalmol 2005; 140: 930-931.

3 Health Intelligence Improving diabetes healthcare, Diabetic eye screening. Available at: www.diabetes.org.uk (accessed on 7 November 2013).

4 Holl RW, Lang GE, Grabert M, Heinze E, Lang GK, Debatin KM. Diabetic retinopathy in paediatric patients with type-1 diabetes: effects of diabetes duration, prepubertal and pubertal onset of diabetes, and metabolic control. J Pediatr 1998; 132: 790-794.

5 Dahlquist G, Rudberg S. The prevalence of microalbumiuria in diabetic children and adolescents and its relation to puberty. Acta Paediatr Scand 1987; 76: 795-800.

6 Diabetic retinopathy screening and prevention in children and young people. Available at http://www. diabeticretinopathy.org.uk/childrenretinopathy.html (accessed on 7 November 2013).

7 Sultan MB, Starita C, Huang K. Epidemiology, risk factors and management of paediatric diabetic retinopathy. $\mathrm{Br} \mathrm{J}$ Ophthalmol 2012; 96(3): 312-317.

8 Massin P, Erginay A, Mercat-Caudal I, Vol S, Robert N, Reach $G$ et al. Prevalence of diabetic retinopathy in children and adolescents with type- 1 diabetes attending summer camps in France. Diabetes Metab 2007; 33: 284-289.

9 Kernell A, Dedorsson I, Johansson B, Wickström CP, Ludvigsson J, Tuvemo T et al. Prevalence of diabetic retinopathy in children and adolescents with IDDM: a population based multicentre study. Diabetologia 1997; 40: 307-310.

10 Donaghue KC, Fairchild JM, Chan A, Hing SJ, Howard NJ, Silink M. Diabetes complication screening in 937 children and adolescents. J Pediatr Endocrinol Metab 1999; 12: 185-192.

11 Lueder GT, Silverstein J. Screening for retinopathy in the pediatric patient with type 1 diabetes mellitus. Pediatrics 2005; 116: 270-273.

12 Harding S, Greenwood R, Aldington S, Gibson J, Owens D, Taylor $\mathrm{R}$ et al. Grading and disease management in national screening for diabetic retinopathy in England and Wales. Diabet Med 20(12): 965-971.

13 Burger W, Hovener G, Dusterhus R, Hartmann R, Weber B. Prevalence and development of retinopathy in children and adolescents with type 1 diabetes mellitus. A longitudinal study. Diabetologia 1986; 29: 17-22.

14 Gallego PH, Craig ME, Hing S, Donaghue KC. Role of blood pressure in development of early retinopathy in adolescents with type 1 diabetes: prospective cohort study. BMJ 2008; 337: a918. 